\title{
Synthesis and Single Crystal X-Ray Structure of 2-(1,3,4-Oxadiazol- 2-yl)aniline
}

\author{
Ali Souldozi ${ }^{\mathrm{a}, \mathrm{b}}$, Katarzyna Ślepokura ${ }^{\mathrm{c}}$, Tadeusz Lis ${ }^{\mathrm{c}}$, and Ali Ramazani ${ }^{\mathrm{b}}$ \\ a Department of Chemistry, Islamic Azad University-Urmia Branch, P O Box 969, Urmia, Iran \\ $\mathrm{b}$ Department of Chemistry, the University of Zanjan, P O Box 45195-313, Zanjan, Iran \\ ${ }^{c}$ Faculty of Chemistry, University of Wrocław, 14 Joliot-Curie St., 50-383 Wrocław, Poland \\ Reprint requests to Dr. A. Ramazani. Fax: +98 241 5283100. E-mail: aliramazani@yahoo.com
}

Z. Naturforsch. 2007, 62b, 835-840; received February 5, 2007

Reaction of 2-aminobenzoic acid with ( $N$-isocyanimino)triphenylphosphorane proceeds smoothly at r.t. to afford 2-(1,3,4-oxadiazol-2-yl)aniline in high yield. The structure of this compound was confirmed by IR, ${ }^{1} \mathrm{H}$, and ${ }^{13} \mathrm{C}$ NMR spectroscopy, mass spectrometry, and single crystal X-ray structure determination. The X-ray structural analysis of the product indicated that its aromatic rings are approximately co-planar.

Key words: 2-Aminobenzoic Acid, ( $N$-Isocyanimino)triphenylphosphorane, 2-(1,3,4-Oxadiazol-2yl)aniline, $A z a$-Wittig Reaction, Crystal Structure Determination

\section{Introduction}

1,3,4-Oxadiazoles have attracted interest in medicinal chemistry as surrogates of carboxylic acids, esters, and carboxamides. They are an important class of heterocyclic compounds that have a wide range of pharmaceutical and biological activities being, among others, anti-microbial, anti-fungal, anti-inflammatory, and anti-hypertensive $[1-5]$. Several methods have been reported in the literature for the synthesis of 1,3,4-oxadiazoles. These protocols are routinely multistep in nature [6-11]. The most general method involves the cyclization of diacylhydrazides with a variety of reagents, such as thionyl chloride, phosphorus oxychloride, and sulfuric acid, usually under harsh reaction conditions. Few reliable and operationally facile processes have been reported for the one step synthesis of 1,3,4-oxadiazoles, especially from readily available carboxylic acids and acid hydrazides [12-16]. In the last years several synthetic methods have been reported for the preparation of $(N$ isocyanimino)triphenylphosphorane $\left(\mathrm{CNNPPh}_{3}\right)$ (2) (Scheme 1) [17-18]. There are several reports for the use of ( $N$-isocyanimino)triphenylphosphorane (2) in the synthesis of metal complexes [17-18]. However, application of ( $N$-isocyanimino)triphenylphosphorane (2) in the synthesis of organic compounds has not been reported. As part of our ongoing program to develop efficient and robust methods for the preparation of het-
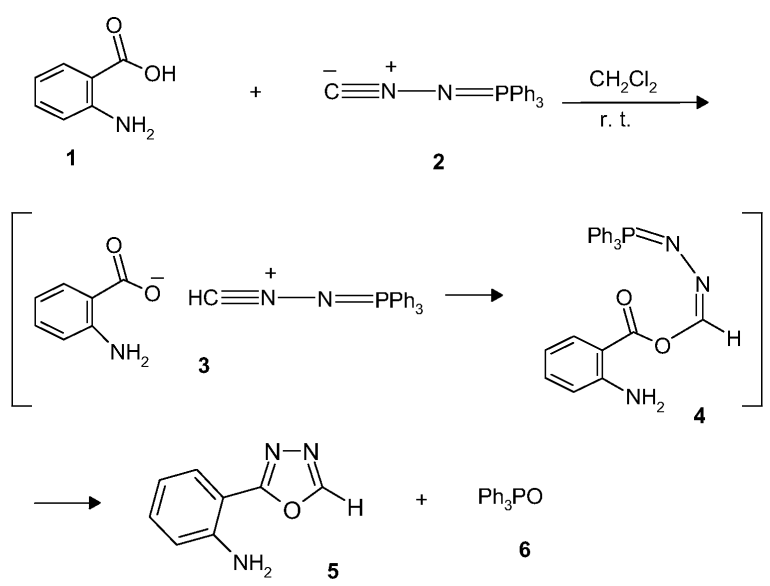

Scheme 1.

erocyclic compounds [19-21], we sought to examine the reaction of 2-aminobenzoic acid (1) with $(N$ isocyanimino)triphenylphosphorane (2) (Scheme 1). In this paper, we describe the synthesis and crystal structure of 2-(1,3,4-oxadiazol-2-yl)aniline.

\section{Results and Discussion}

2-Aminobenzoic acid (1) and ( $N$-isocyanimino)triphenylphosphorane (2) in dichloromethane undergo a smooth $1: 1$ addition reaction at $r$.t. to produce 2-(1,3,4-oxadiazol-2-yl)aniline (5) and triphenylphosphine oxide (6) (Scheme 1). The reaction proceeds 
Table 1. Crystal data and structure refinement details for $\mathbf{5}$.

\begin{tabular}{|c|c|}
\hline \multicolumn{2}{|l|}{ Crystal data: } \\
\hline Empirical formula & $\mathrm{C}_{8} \mathrm{H}_{7} \mathrm{~N}_{3} \mathrm{O}$ \\
\hline Formula weight, $\mathrm{g} \mathrm{mol}^{-1}$ & 161.17 \\
\hline Crystal system, space group & monoclinic, $P 2{ }_{1} / n$ \\
\hline$a[\AA]$ & $10.547(3)$ \\
\hline$b[\AA]$ & $9.801(3)$ \\
\hline$c[\AA]$ & $14.460(4)$ \\
\hline$\beta$ [deg] & 101.07(3) \\
\hline$V\left[\AA^{3}\right]$ & $1466.9(7)$ \\
\hline$Z$ & 8 \\
\hline$D_{\text {calc }}\left[\mathrm{g} \mathrm{cm}^{-3}\right]$ & 1.459 \\
\hline$\mu\left[\mathrm{mm}^{-1}\right]$ & 0.102 \\
\hline$F(000)[\mathrm{e}]$ & 672 \\
\hline Crystal size $\left[\mathrm{mm}^{3}\right]$ & $0.50 \times 0.50 \times 0.42$ \\
\hline Crystal color and form & yellowish block \\
\hline \multicolumn{2}{|l|}{ Data collection: } \\
\hline Diffractometer & Kuma KM4CCD \\
\hline Data collection method & $\omega$ scans \\
\hline Monochromator & graphite \\
\hline Radiation type, $\lambda[\AA]$ & $\operatorname{MoK}_{\alpha}, 0.71073$ \\
\hline$T, \mathrm{~K}$ & $100(2)$ \\
\hline$\theta$ Range $[\mathrm{deg}]$ & $3.37-29.98$ \\
\hline$h, k, l$ Ranges & $\begin{array}{l}-13 \leq h \leq 14,-12 \leq k \leq 12, \\
-19 \leq l \leq 20\end{array}$ \\
\hline Measured reflections & $1228 \overline{3}-$ \\
\hline Independent reflections & 3866 \\
\hline Observed refl. $[I \geq 2 \sigma(I)]$ & 2897 \\
\hline Completeness to $\bar{\theta}=30.00^{\circ}$ & 0.998 \\
\hline \multicolumn{2}{|l|}{ Refinement: } \\
\hline Refinement on & $F^{2}$ \\
\hline Data/restraints/parameters & $3866 / 0 / 273$ \\
\hline$R\left[F_{\mathrm{o}}^{2} \geq 2 \sigma\left({F_{\mathrm{o}}}^{2}\right)\right]$ & $R 1=0.0405, w R 2=0.1039$ \\
\hline$R$ (all data) & $R 1=0.0557, w R 2=0.1094$ \\
\hline $\mathrm{GooF}=S$ & 1.008 \\
\hline Weighting parameter $a / b$ & $0.0740 / 0.0$ \\
\hline$\Delta \rho_{\max } / \Delta \rho_{\min }\left[\mathrm{e} \AA^{-3}\right]$ & $0.29 /-0.28$ \\
\hline
\end{tabular}

$R 1=\Sigma|| F_{\mathrm{o}}|-| F_{\mathrm{c}} \| / \Sigma\left|F_{\mathrm{o}}\right| ; w R 2=\sqrt{\sum\left[w\left(F_{\mathrm{o}}^{2}-F_{\mathrm{c}}^{2}\right)^{2}\right] / \Sigma\left[w\left(F_{\mathrm{o}}^{2}\right)^{2}\right]} ;$ weighting scheme: $w=1 /\left[\sigma^{2}\left(F_{\mathrm{o}}^{2}\right)+(a P)^{2}+b P\right]$ where $P=\left(F_{\mathrm{o}}^{2}+\right.$ $\left.2 F_{\mathrm{c}}^{2}\right) / 3$.

smoothly and cleanly under mild conditions and no side reactions were observed. The mechanism of the reaction between $\mathbf{1}$ and $\mathbf{2}$ has not been established experimentally. However, a possible explanation is proposed in Scheme 1. On the basis of the well established chemistry of isocyanides [22], it is reasonable to assume that protonation of the zwitterionic isocyanide $\mathbf{2}$ by 2 -aminobenzoic acid (1), followed by quenching of the cationic center by the conjugate base of the acid, can generate the iminophosphorane 4 [23]. Intramolecular $a z a$-Wittig [23] reaction of the iminophosphorane 4 leads to the formation of the 2-(1,3,4-oxadiazol-2-yl)aniline (5) and triphenylphosphine oxide (6). The structure of the 2-(1,3,4-oxadiazol-2-yl)aniline (5) was confirmed by IR, ${ }^{1} \mathrm{H}$, and ${ }^{13} \mathrm{C}$ NMR spectroscopy, mass spectrometry, and single crystal X-ray structure
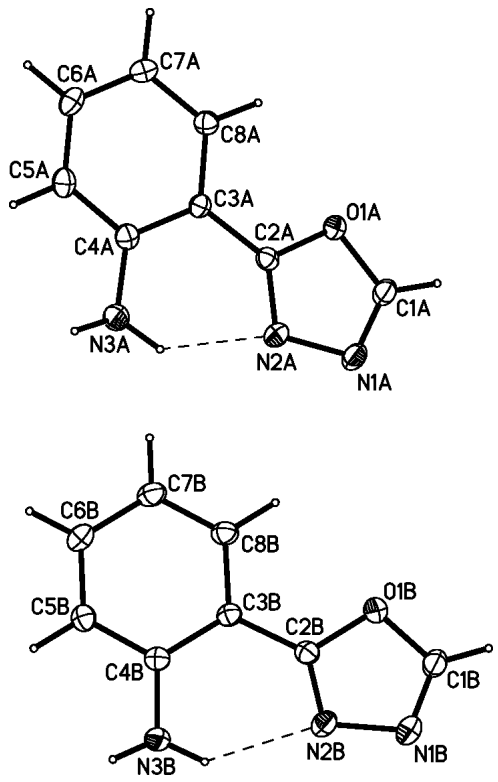

Fig. 1. The molecular structures of the two crystallographically independent molecules (denoted as A and B) present in the crystal of $\mathbf{5}$, showing the atom numbering scheme and the intramolecular $\mathrm{N}-\mathrm{H} \cdots \mathrm{N}$ hydrogen contacts forming $S(6)$ motifs (dashed lines). Displacement ellipsoids are shown at the $40 \%$ probability level.

determination (see Experimental Section).

\section{Description of the crystal structure of 5}

The asymmetric unit of the crystal of compound $\mathbf{5}$ contains two chemically identical molecules of 2(1,3,4-oxadiazol-2-yl)aniline (denoted as A and B). The molecular structures of $\mathrm{A}$ and $\mathrm{B}$ are shown in Fig. 1 and a summary of the experimental details is given in Table 1. The molecules are planar with r.m.s. deviations of fitted atoms at $0.051 \AA$ for $\mathrm{A}$ and $0.062 \AA$ for B. In both molecules maximum deviation from the least-squares planes is observed for atom $\mathrm{O}$ (1) $[0.094(1) \AA$ in A and 0.103(1) $\AA$ in B], which was also observed for the close analogue of $\mathbf{5}$, its 2-carbonyl derivative 5-(2-aminophenyl)-1,3,4-oxadiazol-2(3H)-one [24].

The two parts of each molecule are almost exactly planar [with r.m.s. of fitted atoms of 0.001, 0.005, 0.002 and $0.009 \AA$ for oxadiazole and aminophenyl moieties of $\mathrm{A}$ and $\mathrm{B}$, respectively, with maximum deviations less than 0.014(1) $\AA$, and with an angle between the least-squares planes through oxadiazole and the aminophenyl moieties of $6.2(1)^{\circ}$ for A and 7.2(1) for B]. The geometry of the two molecules is the same 
Table 2. Selected interatomic distances $(\AA)$, valence angles (deg) and torsion angles (deg) in $\mathbf{5}$.

\begin{tabular}{lll}
\hline & Molecule A & Molecule B \\
\hline Bond lengths: & & \\
$\mathrm{O}(1)-\mathrm{C}(1)$ & $1.357(2)$ & $1.358(2)$ \\
$\mathrm{O}(1)-\mathrm{C}(2)$ & $1.371(2)$ & $1.372(2)$ \\
$\mathrm{N}(1)-\mathrm{N}(2)$ & $1.416(2)$ & $1.412(2)$ \\
$\mathrm{N}(1)-\mathrm{C}(1)$ & $1.280(2)$ & $1.280(2)$ \\
$\mathrm{N}(2)-\mathrm{C}(2)$ & $1.302(2)$ & $1.300(2)$ \\
$\mathrm{N}(3)-\mathrm{C}(4)$ & $1.376(2)$ & $1.376(2)$ \\
$\mathrm{C}(2)-\mathrm{C}(3)$ & $1.450(2)$ & $1.450(2)$ \\
$\mathrm{C}(3)-\mathrm{C}(4)$ & $1.416(2)$ & $1.419(2)$ \\
Bond angles: & & \\
$\mathrm{C}(1)-\mathrm{O}(1)-\mathrm{C}(2)$ & $102.59(8)$ & $102.41(9)$ \\
$\mathrm{C}(1)-\mathrm{N}(1)-\mathrm{N}(2)$ & $105.44(9)$ & $105.41(9)$ \\
$\mathrm{C}(2)-\mathrm{N}(2)-\mathrm{N}(1)$ & $106.61(9)$ & $106.81(9)$ \\
$\mathrm{N}(1)-\mathrm{C}(1)-\mathrm{O}(1)$ & $113.87(10)$ & $113.88(10)$ \\
$\mathrm{N}(2)-\mathrm{C}(2)-\mathrm{O}(1)$ & $111.49(9)$ & $11.49(10)$ \\
$\mathrm{O}(1)-\mathrm{C}(2)-\mathrm{C}(3)$ & $118.72(8)$ & $129.15(10)$ \\
$\mathrm{N}(2)-\mathrm{C}(2)-\mathrm{C}(3)$ & $129.78(9)$ & \\
Torsion angles: & & $172.4(1)$ \\
$\mathrm{N}(2)-\mathrm{C}(2)-\mathrm{C}(3)-\mathrm{C}(8)$ & $173.2(1)$ & $176.1(1)$ \\
$\mathrm{O}(1)-\mathrm{C}(2)-\mathrm{C}(3)-\mathrm{C}(4)$ & $175.3(1)$ & $-4.7(2)$ \\
$\mathrm{C}(8)-\mathrm{C}(3)-\mathrm{C}(4)-\mathrm{N}(3)$ & $179.0(1)$ & $177.5(1)$ \\
$\mathrm{C}(2)-\mathrm{C}(3)-\mathrm{C}(4)-\mathrm{N}(3)$ & $-2.2(2)$ & \\
$\mathrm{C}(2)-\mathrm{C}(3)-\mathrm{C}(4)-\mathrm{C}(5)$ & $179.6(1)$ & \\
\hline & &
\end{tabular}

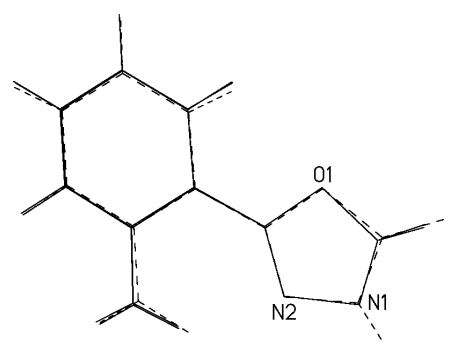

Fig. 2. Comparison of the molecular structures of the two crystallographically independent molecules of $2-(1,3,4-$ oxadiazol-2-yl)aniline (5; solid lines) with its 2-carbonyl derivative: 5-(2-aminophenyl)-1,3,4-oxadiazol-2(3H)-one [24] (atomic coordinates from Ref. [25]; dashed lines). The common reference points are $\mathrm{O}(1), \mathrm{N}(1)$ and $\mathrm{N}(2)$.

within experimental error, which is clearly indicated by the geometrical parameters listed in Table 2 and is easy to see when superimposing the molecular structures of A and B (see Fig. 2). Additionally, which is also shown in Fig. 2, the overall geometry of A and $\mathrm{B}$ is very close to that observed in 5-(2-aminophenyl)1,3,4-oxadiazol-2(3H)-one [24, 25$]$.

The pyramidalization of the amino group is not so expressed as observed in crystalline aniline [26]. Both $\mathrm{N}(3)$ atoms lie nearly exactly in the phenyl ring planes (they are coplanar within $0.02 \AA$ in $\mathrm{A}$ and $0.03 \AA$ in $B)$, whereas the hydrogen atoms are slightly displaced from these planes [the distances of atoms $\mathrm{H}(31 \mathrm{~A})$,
$\mathrm{H}(32 \mathrm{~A}), \mathrm{H}(31 \mathrm{~B})$ and $\mathrm{H}(32 \mathrm{~B})$ from the respective $\mathrm{Ph}$ ring planes are in the range of $0.12-0.23 \AA]$. The dihedral angle between the planes defined by the amino group and the phenyl ring is $22(2)^{\circ}$ in A and $28(2)^{\circ}$ in $\mathrm{B}$, compared to $37-38^{\circ}$ in the crystal structure of the free aniline [26] and about $16^{\circ}$ in 5-(2-aminophenyl)-1,3,4-oxadiazol-2(3H)-one [24,25]. The sum of the angles about $\mathrm{N}(3)$ is $355(2)^{\circ}$ in $\mathrm{A}$ and $351(2)^{\circ}$ in $\mathrm{B}$, compared to $360^{\circ}$ typical for a planar, trigonal environment with a $s p^{2}$-hybridized atom, about $330^{\circ}$ at a tetrahedral $s p^{3}$-hybridized $\mathrm{N}$, about $340^{\circ}$ in crystalline aniline [26], or about $356^{\circ}$ in 5-(2-aminophenyl)-1,3,4-oxadiazol-2(3H)-one [24,25]. All that indicates a rather small degree of pyramidalization of the amine $\mathrm{N}(3)$ atoms in compound $\mathbf{5}$, as well as in its close analogue, the 2-carbonyl derivative. There is also a slight shortening of $\mathrm{N}(3)-\mathrm{C}(4))(1.376(2) \AA$ in both $\mathrm{A}$ and $\mathrm{B}$, and 1.373(4) $\AA$ in 5-(2-aminophenyl)1,3,4-oxadiazol-2(3H)-one [24]) as compared to typical $\mathrm{C}_{\mathrm{ar}}-\mathrm{NH}_{2 \text { (pyramidal) }}$ systems [27].

The overall planar geometry of the molecules is stabilized by the intramolecular $\mathrm{N}(3)-\mathrm{H}(31) \cdots \mathrm{N}(2)$ hydrogen bond forming the usual six-membered $S(6)$ motif, also shown in Fig. 1. It is possible that the intramolecular $\mathrm{N}-\mathrm{H} \cdots \mathrm{N}$ hydrogen bond may be assisted by resonance, which is often observed when the hydrogen-bond donor and acceptor are connected by a short chain of conjugated single and double bonds [28] [compare the geometry of the fragment involved in the $S(6)$ ring motif: $\mathrm{H}(31)-\mathrm{N}(3)-\mathrm{C}(4)-\mathrm{C}(3)-$ $\mathrm{C}(2)-\mathrm{N}(2)$; Tables 2 and 3]. Similar intramolecular $\mathrm{N}-\mathrm{H} \cdots \mathrm{N}$ contacts are observed in 5-(2-aminophenyl)1,3,4-oxadiazol-2(3H)-one [24].

In the crystals of $\mathbf{5}$, adjacent molecules $\mathrm{A}$ and $\mathrm{B}$ are linked by a rather extensive network of $\mathrm{N}-$ $\mathrm{H} \cdots \mathrm{N}$ hydrogen bonds and $\mathrm{C}-\mathrm{H} \cdots \mathrm{N} / \mathrm{O}$ close interactions to form two independent chains (denoted as chain $\mathrm{A}$ and chain $\mathrm{B}$ ), both parallel to the $b$ axis, as shown in Fig. 3. Most of the interactions are formed within the respective chain $\mathrm{A}$ or $\mathrm{B}$, however two types of them, i.e. $\mathrm{C}(1 \mathrm{~B})-\mathrm{H}(1 \mathrm{~B}) \cdots \mathrm{N}(3 \mathrm{~A})^{\mathrm{iv}}$ and $\mathrm{C}(5 \mathrm{~B})-$ $\mathrm{H}(5 \mathrm{~B}) \cdots \mathrm{O}(1 \mathrm{~A})^{\mathrm{v}}$ [equivalent $\mathrm{C}(5 \mathrm{~B})^{\mathrm{ii}}-\mathrm{H}(5 \mathrm{~B})^{\mathrm{ii}} \ldots \mathrm{O}(1 \mathrm{~A})^{\mathrm{i}}$ is shown in Fig. 3], act as linkers between the independent chains $\mathrm{A}$ and $\mathrm{B}$. The other weak contact, $\mathrm{C}(1 \mathrm{~A})-\mathrm{H}(1 \mathrm{~A}) \cdots \mathrm{N}(1 \mathrm{~A})^{\mathrm{iii}}$, is formed between two adjacent chains of the same type A. Despite very similar overall structures of the respective chains A and $\mathrm{B}$, the network of hydrogen contacts is quite different, which is easy to see in Fig. 3. A short non-bonding, rather repulsive, inter $\mathrm{D}-\mathrm{H} \cdots \mathrm{H}-\mathrm{X}$ con- 
Table 3. Geometry of proposed hydrogen bonds and $\mathrm{N}-\mathrm{H} \cdots \mathrm{N}, \mathrm{C}-\mathrm{H} \cdots \mathrm{N} / \mathrm{O}$ close contacts, and $\pi \cdots \pi$ stacking interactions for $5(\AA, d e g)$.

\begin{tabular}{|c|c|c|c|c|c|c|c|}
\hline $\bar{D}-\mathrm{H} \cdots \mathrm{A}$ & $\begin{array}{c}\mathrm{D}-\mathrm{H} \\
(\AA)\end{array}$ & $\begin{array}{c}\mathrm{H} \cdots \mathrm{A} \\
(\AA)\end{array}$ & $\begin{array}{c}\text { D ... A } \\
(\AA)\end{array}$ & $\begin{array}{c}\mathrm{D}-\mathrm{H} \cdots \mathrm{A} \\
(\mathrm{deg})\end{array}$ & $\begin{array}{l}\pi \cdots \pi \text { stacking } \\
\text { interactions }\end{array}$ & $\begin{array}{c}C \mathrm{~g} \cdots C \mathrm{~g} \\
(\AA)\end{array}$ & $\begin{array}{c}\text { dihedral } \\
\text { angle (deg) }\end{array}$ \\
\hline $\bar{N}(3 \mathrm{~A})-\mathrm{H}(31 \mathrm{~A}) \cdots \mathrm{N}(2 \mathrm{~A})$ & $0.90(2)$ & $2.08(2)$ & $2.788(2)$ & $135(2)$ & $\overline{C g}(1) \cdots C g(2)^{\mathrm{vII}}$ & $3.583(2)$ & 6.03 \\
\hline $\mathrm{N}(3 \mathrm{~A})-\mathrm{H}(32 \mathrm{~A}) \cdots \mathrm{N}(1 \mathrm{~A})^{\mathrm{i}}$ & $0.88(2)$ & $2.53(2)$ & $3.400(2)$ & $166(2)$ & $C g(2) \cdots C g(1)^{\mathrm{vii}}$ & $3.583(2)$ & 6.03 \\
\hline $\mathrm{N}(3 \mathrm{~B})-\mathrm{H}(31 \mathrm{~B}) \cdots \mathrm{N}(2 \mathrm{~B})$ & $0.90(2)$ & $2.09(2)$ & $2.782(2)$ & $133(1)$ & $C g(2) \cdots C g(4)^{\mathrm{i}}$ & $3.710(2)$ & 7.27 \\
\hline $\mathrm{N}(3 \mathrm{~B})-\mathrm{H}(32 \mathrm{~B}) \cdots \mathrm{N}(1 \mathrm{~B})^{\mathrm{ii}}$ & $0.90(2)$ & $2.35(2)$ & $3.248(2)$ & $174(2)$ & $C g(3) \cdots C g(4)^{\mathrm{viii}}$ & $3.582(2)$ & 6.83 \\
\hline $\mathrm{C}(1 \mathrm{~A})-\mathrm{H}(1 \mathrm{~A}) \cdots \mathrm{N}(1 \mathrm{~A})^{\mathrm{iii}}$ & $0.97(2)$ & $2.78(2)$ & $3.503(2)$ & 132(1) & $C g(4) \cdots C g(2)^{\mathrm{ix}}$ & $3.710(2)$ & 7.27 \\
\hline $\mathrm{C}(5 \mathrm{~A})-\mathrm{H}(5 \mathrm{~A}) \cdots \mathrm{N}(2 \mathrm{~A})^{\mathrm{i}}$ & $0.99(2)$ & $2.79(2)$ & $3.687(2)$ & $150(1)$ & $C g(4) \cdots C g(3)^{\mathrm{viii}}$ & $3.582(2)$ & 6.83 \\
\hline $\mathrm{C}(5 \mathrm{~A})-\mathrm{H}(5 \mathrm{~A}) \cdots \mathrm{N}(3 \mathrm{~A})^{\mathrm{i}}$ & $0.99(2)$ & $2.78(2)$ & $3.667(2)$ & $149(1)$ & & & \\
\hline $\mathrm{C}(1 \mathrm{~B})-\mathrm{H}(1 \mathrm{~B}) \cdots \mathrm{N}(3 \mathrm{~A})^{\mathrm{iv}}$ & $0.94(2)$ & $2.68(2)$ & $3.344(2)$ & $128(1)$ & & & \\
\hline $\mathrm{C}(5 \mathrm{~B})-\mathrm{H}(5 \mathrm{~B}) \cdots \mathrm{O}(1 \mathrm{~A})^{\mathrm{v}}$ & $0.98(2)$ & $2.73(2)$ & $3.251(2)$ & $114(1)$ & & & \\
\hline $\mathrm{C}(5 \mathrm{~B})-\mathrm{H}(5 \mathrm{~B}) \cdots \mathrm{N}(2 \mathrm{~B})^{\mathrm{ii}}$ & $0.98(2)$ & $2.65(2)$ & $3.463(2)$ & $140(1)$ & & & \\
\hline $\mathrm{C}(6 \mathrm{~B})-\mathrm{H}(6 \mathrm{~B}) \cdots \mathrm{N}(1 \mathrm{~B})^{\mathrm{vi}}$ & $0.96(2)$ & $2.76(2)$ & $3.624(2)$ & $150(1)$ & & & \\
\hline
\end{tabular}

Symmetry codes: ${ }^{\mathrm{i}}-x+1 / 2, y-1 / 2,-z+3 / 2 ;{ }^{\mathrm{ii}}-x+3 / 2, y-1 / 2,-z+3 / 2 ;{ }^{\mathrm{iii}}-x,-y+1,-z+1 ;{ }^{\mathrm{i}} x, y+1, z ;{ }^{\mathrm{v}} x+1, y, z ;{ }^{\mathrm{vi}} x, y-1$, $z ;{ }^{\text {vii }}-x,-y,-z+1$; ${ }^{\text {vii }}-x+1,-y+1,-z+1$; ${ }^{\text {ix }}-x+1 / 2, y+1 / 2,-z+3 / 2 .-C g(1), C g(2), C g(3)$ and $C g(4)$ are the centroids of the 1,3,4-oxadiazolyl and aniline phenyl rings from molecules $\mathrm{A}$ and $\mathrm{B}$, respectively, i.e. $\mathrm{O}(1 \mathrm{~A}) / \mathrm{C}(1 \mathrm{~A}) / \mathrm{N}(1 \mathrm{~A}) / \mathrm{N}(2 \mathrm{~A}) / \mathrm{C}(2 \mathrm{~A}), \mathrm{C}(3 \mathrm{~A})-\mathrm{C}(8 \mathrm{~A})$ and $\mathrm{O}(1 \mathrm{~B}) / \mathrm{C}(1 \mathrm{~B}) / \mathrm{N}(1 \mathrm{~B}) / \mathrm{N}(2 \mathrm{~B}) / \mathrm{C}(2 \mathrm{~B}), \mathrm{C}(3 \mathrm{~B})-\mathrm{C}(8 \mathrm{~B})$.

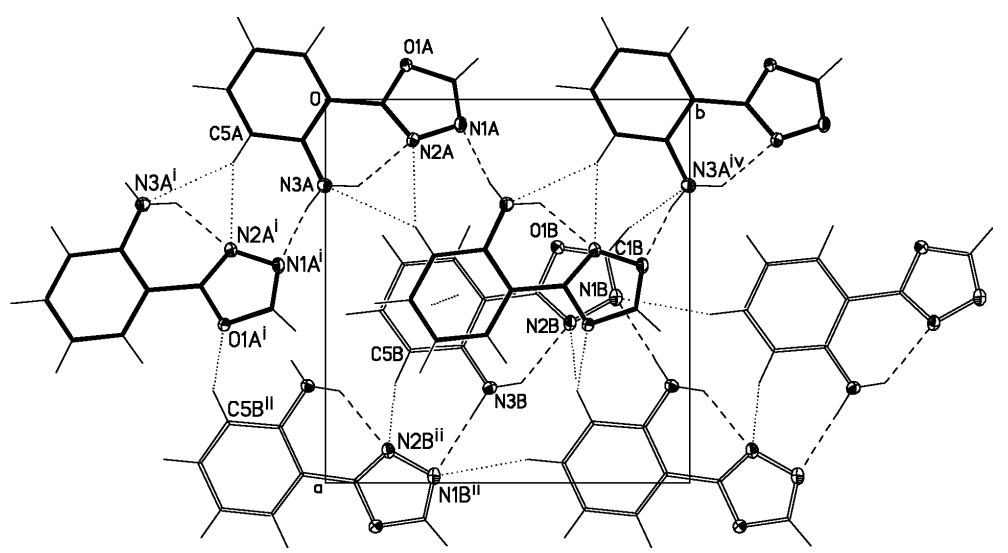

Fig. 3. The arrangement of the molecules A (solid lines) and B (open lines) within the chains running parallel to the $b$ axis; viewed down the $c$ axis. Intra- and intermolecular $\mathrm{N}-\mathrm{H} \cdots \mathrm{N}$ hydrogen bonds are shown with dashed lines, and intermolecular $\mathrm{C}-\mathrm{H} \cdots \mathrm{N} / \mathrm{O}$ close contacts and weak $\pi \cdots \pi$ stacking interactions with dotted lines. Symmetry codes are given in Table 3 . tact is observed in chain A. It is formed between atoms $\mathrm{H}(5 \mathrm{~A})$ and $\mathrm{H}(31 \mathrm{~A})^{\mathrm{i}}$ [with a $\mathrm{H}(5 \mathrm{~A}) \cdots \mathrm{H}(31 \mathrm{~A})^{\mathrm{i}}$ distance of $2.04(2) \AA]$ and accompanies the weak, bifurcated $\mathrm{C}(5 \mathrm{~A})-\mathrm{H}(5 \mathrm{~A}) \cdots \mathrm{N}(2 \mathrm{~A})^{\mathrm{i}} / \mathrm{N}(3 \mathrm{~A})^{\mathrm{i}}$ interaction, which in combination with intramolecular $\mathrm{N}(3 \mathrm{~A})$ $\mathrm{H}(31 \mathrm{~A}) \cdots \mathrm{N}(2 \mathrm{~A})$ hydrogen bonds, gives rise to $R_{2}^{2}(4)$ rings formed between two adjacent molecules $\mathrm{A}$ in chain A.

Beside different intra- and interchain $\mathrm{N}-\mathrm{H} \cdots \mathrm{N}$ and $\mathrm{C}-\mathrm{H} \cdots \mathrm{N} / \mathrm{O}$ interactions, the molecules of adjacent chains $\mathrm{A}$ and $\mathrm{B}$ are stacked through $\pi \cdots \pi$ interactions along the $c$ axis, with a ring-centroid separation of $3.582(2)-3.710(2) \AA$ and the angles between the planes of the stacking rings in the range of $6.03-7.27^{\circ}$ (Table 3, Fig. 3).

\section{Conclusions}

We believe the reported method offers a mild, simple and efficient route for the preparation of 2-(1,3,4- oxadiazol-2-yl)aniline (5). The ease of work up, high yield and fairly mild reaction conditions make it a useful addition to modern synthetic methodologies. Other aspects of this process are under investigation. The $\mathrm{X}$-ray structural analysis of the product indicated that the two aromatic rings of the molecule are approximately co-planar.

\section{Experimental Section}

\section{General procedures}

Freshly distilled solvents were used throughout, and anhydrous solvents were dried according to Perrin and Armarego [29]. Elemental analyses were performed using a Heraeus CHN-O-Rapid analyzer. ${ }^{1} \mathrm{H}(250 \mathrm{MHz})$ and ${ }^{13} \mathrm{C}(62.5 \mathrm{MHz})$ NMR measurements were recorded on a Bruker 250 spectrometer in $\mathrm{CDCl}_{3}$ with tetramethylsilane as internal standard. IR spectra were measured on a Shimadzu IR-460 spectrometer. Mass spectra were 
recorded on a FINNIGAN-MAT 8430 mass spectrometer operating at an ionization potential of $20 \mathrm{eV}$. Melting points were measured on an Electrothermal 9100 apparatus and are uncorrected. ( $N$-Isocyanimino)triphenylphosphorane (2) was prepared based on a reported procedure [17]. Other starting materials and solvents were obtained from Merck (Germany) and Fluka (Switzerland) and were used without further purification. Flash chromatography columns were prepared from Merck silica gel powder.

\section{2-(1,3,4-Oxadiazol-2-yl)aniline (5)}

To a magnetically stirred solution of ( $N$-isocyanimino) triphenylphosphorane $2(0.302 \mathrm{~g}, 1 \mathrm{mmol})$ in dry $\mathrm{CH}_{2} \mathrm{Cl}_{2}$ $(8 \mathrm{~mL})$ was added dropwise a mixture of 2-amino benzoic acid $1(0.137 \mathrm{~g}, 1 \mathrm{mmol})$ in dry $\mathrm{CH}_{2} \mathrm{Cl}_{2}(7 \mathrm{~mL})$ over $15 \mathrm{~min}$. The mixture was stirred for $6 \mathrm{~h}$ at r.t. The solvent was removed under reduced pressure and the viscous residue was purified by flash column chromatography [silica gel; petroleum ether-ethyl acetate $(10: 2)]$. The solvent was removed under reduced pressure and the product 4 was obtained as light yellow crystals. Yield: $140 \mathrm{mg}$ (86\%); m. p. $145.3{ }^{\circ} \mathrm{C}$. - IR (KBr): $v=3431,3339,3039,2939,2931$, 2931, 1623, 1269, 1108, $754 \mathrm{~cm}^{-1}$. - ${ }^{1} \mathrm{H} \mathrm{NMR}\left(\mathrm{CDCl}_{3}\right)$ : $\delta=5.69$ (br. s, $2 \mathrm{H}, \mathrm{NH}_{2}$ ), 6.73 (s, $1 \mathrm{H}$, arom.), 6.79 (t, $1 \mathrm{H},{ }^{3} J=7.5 \mathrm{~Hz}$, arom.), $7.75\left(\mathrm{t}, 1 \mathrm{H},{ }^{3} J=7.8 \mathrm{~Hz}\right.$, arom.), 7.76 (d, $1 \mathrm{H},{ }^{3} J=6.0 \mathrm{~Hz}$, arom.), 8.41 (s, $1 \mathrm{H}$, oxadiazole). $-{ }^{13} \mathrm{C} \mathrm{NMR}\left(\mathrm{CDCl}_{3}\right): \delta=116.28,116.91,127.99$ and 132.79 (4 CH, arom.); 105.38 and 147.01 (2 C, arom.); 150.91 (1 CH, oxadiazole); 164.62 (1 C, oxadiazole). - MS: $\mathrm{m} / \mathrm{z}(\%)=161(100)[\mathrm{M}]^{+}, 120(50), 105(22), 92(25), 90$ (15), 78 (15), 77 ( 34), 65 (28), 63 (21), 58 (22), 55 (11), 52 (20), 51 (31), 50 (18), 43 (28), 41 (21). $-\mathrm{C}_{8} \mathrm{H}_{7} \mathrm{~N}_{3} \mathrm{O}$ (161.06): calcd. C 59.62, H 4.38, N 26.07; found C 59.57, H 4.34, N 26.14.
Preparation of single crystals of 2-(1,3,4-oxadiazol-2-yl)aniline (5)

Single crystals of 5 were prepared by using the branch tube method with $n$-hexane at $40{ }^{\circ} \mathrm{C}$ during two weeks [30]. The light yellow crystals were filtered off, washed with cold $n$-hexane and dried at r.t. (m.p. $145.5^{\circ} \mathrm{C}$ ).

\section{Crystal structure determination of 5}

The crystallographic measurement was performed on a $\kappa$-geometry Kuma KM4CCD automated four-circle diffractometer with the graphite-monochromatized $\mathrm{Mo} K_{\alpha}$ radiation. The data were collected at 100(2) K using the Oxford Cryosystems cooler. A summary of the conditions for the data collection and the structure refinement parameters is given in Table 1. The data were corrected for Lorentz and polarization effects. Data collection, cell refinement, and data reduction and analysis were carried out with the KM4CCD software (Oxford Diffraction, Poland): CrysAlis CCD and CrysAlis RED, respectively [31]. The structure was solved by Direct Methods using SHELXS-97 [32] and refined by fullmatrix least-squares techniques with anisotropic displacement parameters for the non-H atoms using SHELXL-97 [33]. All $\mathrm{H}$ atoms were found in difference Fourier maps and were refined isotropically. All figures were made using the program XP [34].

\section{Supplementary material}

CCDC 635760 contains the supplementary crystallographic data for this paper. These data can be obtained free of charge from The Cambridge Crystallographic Data Centre via www.ccdc.cam.ac.uk/data_request/cif.

\section{Acknowledgement}

The Iranian authors are thankful to the Research Council of the Urmia Islamic Azad University for partial support of this work.
[1] W. R. Tully, C. R. Gardner, R. J. Gillespie, R. Westwood, J. Med. Chem. 1991, 34, 2060-2067.

[2] C. Chen, C. H. Senanayake, T. J. Bill, R. D. Larsen, T. R. Verhoeven, P. T. Reider, J. Org. Chem. 1994, 59, $3738-3741$.

[3] B.S. Holla, R. Gonsalves, S. Shenoy, Eur. J. Med. Chem. 2000, 35, 267-271.

[4] M. J. Crimmin, P. J. Hanlon, N. H. Rogers, G. Walker, J. Chem. Soc., Perkin Trans. 1 1989, $2047-2056$.

[5] U. V. Laddi, S. R. Desai, R. S. Bennur, S. C. Bennur, Ind. J. Heterocycl. Chem. 2002, 11, 319-322.

[6] I. R. Baxendale, S. V. Ley, M. Martinelli, Tetrahedron 2005, 61, 5323-5349.
[7] S. Liras, M. P. Allen, B. E. Segelstein, Synth. Commun. 2000, 30, $437-443$.

[8] B. J. Brown, I. R. Clemens, J. K. Neesom, Synlett 2000, $1,131-133$.

[9] F. T. Coppo, K. A. Evans, T. L. Graybill, G. Burton, Tetrahedron Lett. 2004, 45, 3257 - 3260.

[10] C. T. Brain, J. M. Paul, Y. Loong, P. J. Oakley, Tetrahedron Lett. 1999, 40, 3275 - 3278.

[11] C. T. Brain, S. A. Brunton, Synlett 2001, 3, 382-384.

[12] V. K. Tandon, R. B. Chhor, Synth. Commun. 2001, 31, $1727-1732$.

[13] S. H. Mashraqui, S. G. Ghadigaonkar, R. S. Kenny, Synth. Commun. 2003, 33, 2541-2545. 
[14] F. Bentiss, M. Lagrenee, D. Barbry, Synth. Commun. 2001, 31, $935-938$.

[15] E. Jedlovska, J. Lesko, Synth. Commun. 1994, 24, $1879-1885$.

[16] Y. Wang, D. R. Sauer, S. W. Djuric, Tetrahedron Lett. 2006, 47, $105-108$.

[17] H. Stolzenberg, B. Weinberger, W. P. Fehlhammer, F. G. Pühlhofer, R. Weiss, Eur. J. Inorg. Chem. 2005, $21,4263-4271$.

[18] T. W. Chiu, Y.H. Liu, K. M. Chi, Y. S. Wen, K. L. Lu, Inorg. Chem. 2005, 44, 6425-6430.

[19] I. Yavari, A. Ramazani, A. Yahya-Zadeh, Synth. Commun. 1996, 26, 4495-4499.

[20] A. Ramazani, E. Ahmadi, A.R. Kazemizadeh, L. Dolatyari, N. Noshiranzadeh, I. Eskandari, A. Souldozi, Phosphorus, Sulphur, and Silicon 2005, 180, $2419-2422$.

[21] A. Ramazani, E. Ahmadi, Phosphorus, Sulfur, and Silicon 2006, 181, 2725-2729.

[22] A. Domling, Chem. Rev. 2006, 106, 17-89.

[23] P. Molina, M. J. Vilaplana, Synthesis 1994, 1197 1218.

[24] J. S. Davidson, J. Trotter, Acta Crystallogr. 1996, C52, $3236-3238$.

[25] Cambridge Structural Database (CSD); F.H. Allen, Acta Crystallogr. 2002, B58, 380-388.
[26] M. Fukuyo, K. Hirotsu, T. Higuchi, Acta Crystallogr. 1982, B38, 640-643.

[27] F. H. Allen, O. Kennard, D. G. Watson, L. Brammer, A. G. Orpen, R. Taylor in International Tables for Crystallography, Vol. C (Ed.: A. J.C. Wilson) Kluwer Academic Publishers, Dordrecht, 1992, chapter 9.5.

[28] V. Bertolasi, L. Pretto, G. Gilli, P. Gilli, Acta Crystallogr. 2006, B62, 850-863 and refs. cited herein.

[29] D. D. Perrin, W. L. F. Armarego, Purification of Laboratory Chemicals, Pergamon Press, Oxford, 1988, pp. $20-35$.

[30] A. Ramazani, A. Souldozi, A. Morsali, A. R. Jalilian, Z. Kristallogr. NCS 2004, 219, 247-248.

[31] Kuma KM4CCD software: CrysAlis CCD and CrysAlis RED (ver. 1.171) Oxford Diffraction (Poland) 1995 2003.

[32] G. M. Sheldrick, SHELXS-97. Program for the solution of crystal structures. University of Göttingen, Göttingen (Germany) 1997.

[33] G. M. Sheldrick, SHELXL-97. Program for the refinement of crystal structures. University of Göttingen, Göttingen (Germany) 1997.

[34] XP - Interactive molecular graphics (ver. 5.1), Bruker Analytical X-ray Systems, Karlsruhe (Germany) 1998. 